\title{
The flood event that affected Badajoz in November 1997
}

\author{
P. Lorente ${ }^{1}$, E. Hernández ${ }^{1}$, S. Queralt ${ }^{1}$, and P. Ribera ${ }^{2}$ \\ ${ }^{1}$ Dept. de Física de la Tierra II, Facultad de Ciencias Físicas, Universidad Complutense de Madrid, Spain \\ ${ }^{2}$ Dept. de Física de la Tierra, Facultad de Ciencias Ambientales, Universidad Pablo de Olavide, Sevilla, Spain
}

Received: 28 August 2007 - Revised: 20 January 2008 - Accepted: 1 February 2008 - Published: 9 April 2008

\begin{abstract}
The flooding episode of November 1997 in Badajoz was one of the most dramatic catastrophes in Spain: as a result, there were 21 fatalities and huge financial damages. The main purpose of this work is to assess the prevailing synoptic conditions as well as detailing the mesoscale effects by means of moisture sources and dynamic and thermodynamic instability analysis involved in the November 1997 Spanish severe weather episode. In order to achieve the above, this flood event is described in terms of moisture content evolution by means of individual particle simulation along 3-day back-trajectories. A Lagrangian model is applied in order to characterize the atmospheric particles involved in the focused case (localization, height and specific humidity) which give rise to sudden precipitation stream. Geopotential height and temperature fields were used to describe the synoptic situation. Thermodynamic indices, such as CAPE, SWEAT and KI, and dynamic parameters like potential vorticity anomaly at $330 \mathrm{~K}$ isentropic surface and $\mathrm{Q}$ vector divergence were also calculated in order to complete the analysis and to give a thorough weather frame taking into account the atmospheric instability. The results of this work suggest this flood event was due mainly to strong dynamic instability along with large amounts of moisture advected by a trough, while the thermodynamic instability played a secondary role. Finally, a new methodology based on a technique proposed by Tremblay (2005) has been developed in order to separate the precipitation into stratiform and convective components. It is evident that the event was associated with a predominant convective regime.
\end{abstract}

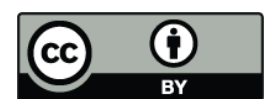

Correspondence to: P. Lorente (pablo_lorente@ fis.ucm.es)

\section{Introduction}

A dramatic heavy rain event took place during the first hours on 6 November 1997 in Badajoz, in southwestern Spain (Fig. 1), causing the overflow of two usually dried brooks, Rivilla and Calamón. Cerro de los Reyes, a small village situated close to the junction of both streams, was flooded violently with subsequent material damages: hundreds of families lost their possessions and 21 people died.

This catastrophe was due to an Atlantic extratropical trough crossing Iberian Peninsula (IP, hereafter) during 46 November 1997, with an orientation from southwest to northeast. The upper low became deeper quickly and extended to lower levels just before leaving the Atlantic Ocean. Large atmospheric instability and the related strong convection played a fundamental role in the development of several Mesoscale Convective Systems (MCSs) associated with the above mentioned low system. Very intense precipitation was observed (with peaks higher than $140 \mathrm{~mm} / 24 \mathrm{~h}$ ) in nearby regions like Huelva, Sevilla, Córdoba and southern areas of Portugal. Moreover; also, strong winds (above $100 \mathrm{~km} / \mathrm{h}$ ) caused enormous material damages in infrastructures and harvests (estimated around 60 million Euros).

The main purpose of this work is to assess the prevailing synoptic conditions as well as detailing the mesoscale effects by means of moisture sources and dynamic and thermodynamic instability analysis involved in the focused severe weather episode. In order to achieve it, on the one hand, the synoptic situation leading to this disaster has been assessed: geopotential height and temperature at $500 \mathrm{hPa}$ level set up the prevailing conditions during the studied event. On the other hand, a new methodology for partitioning precipitation has been developed in order to obtain two different modes: stratiform regime and convective regime (Rogers, 1989; Houze, 1993 and 1997; Trenberth et al., 2003). This procedure, based on the technique proposed by Tremblay (2005), takes into account statistical properties of

Published by Copernicus Publications on behalf of the European Geosciences Union. 


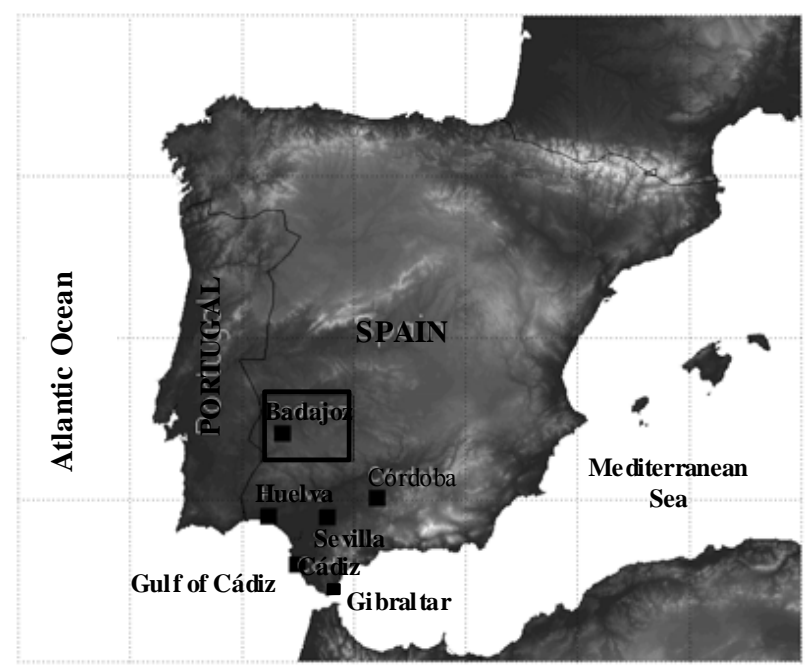

Fig. 1. Study area and location of Badajoz in the box.

in situ rain gauge data, not radar techniques (Lang et al., 2003). It allows us to identify the main MCSs affecting southwestern area of IP and determine basic characteristics of convective regime, ultimately responsible for heavy rain and flood events.

Furthermore, atmospheric instability has been evaluated by means of thermodynamic indices such as SWEAT, KI and CAPE thanks to radiosounding dataset from Gibraltar station. Maps of dynamic parameters like potential vorticity anomaly at $330 \mathrm{~K}$ isentropic surface and $\mathrm{Q}$ vector divergence provide useful information about regions of lifting air where MCSs could have been originated by intense convection.

The Lagrangian model FLEXPART6.2 (Stohl et al., 1998; Stohl and Thompson, 1999) has been applied in order to characterize the atmospheric particles involved in the focused case. It allows to analyze the moisture budget along 3-day backward trajectories and identify humidity sources involved in MCSs development.

This paper is organized as follows. The dataset used in this work is presented in Sect. 2 as well as the new methodology for classifying the precipitation. In Sect. 3 , the results of a brief synoptic study and atmospheric instability analysis are shown. In addition, moisture content evolution is described by means of particle simulation with the model FLEXPART6.2. Finally, section 4 summarizes the main conclusions of this study.

\section{Dataset and methodology}

The synoptic situation and dynamic instability conditions have been evaluated by using the ERA-40 reanalysis over an area defined from $15^{\circ} \mathrm{N}$ to $70^{\circ} \mathrm{N}$ and from $25^{\circ} \mathrm{W}$ to $25^{\circ} \mathrm{E}$, with $2.5^{\circ} \times 2.5^{\circ}$ spatial resolution. Moreover, hourly raingauge dataset during 1997 corresponding to five stations
(Córdoba, Cádiz, Huelva, Badajoz and Sevilla, in Fig. 1), distributed over southwestern IP, have been analyzed. These precipitation time series were provided by the National Meteorological Institute of Spain.

The procedure presented in this work for partitioning the precipitation is based on the technique proposed by Tremblay (2005). An exponential distribution is observed when representing the 6- $\mathrm{h}^{1}$ Accumulated precipitation $P(\mathrm{~mm})$ with respect to precipitation intensity $R(\mathrm{~mm} / 6 \mathrm{~h})$. It thus could be written as follows:

$P(R)=A(t) e^{-B(t) \cdot R}+p^{\prime \prime}=\mathrm{SP}+\mathrm{CP}$

The exponential component, which predominates for small range of intensities, is related to the stratiform regime (SP); the second term, which is more important for large intensities and represents the anomalies of the exponential curve, is associated with convective regime $(\mathrm{CP})$.

The shape of the exponential distribution depends obviously on the chosen class interval width. A criterion has been established in order to select the suitable interval by means of two parameters: on the one hand, the standard deviation of precipitation intensity $\sigma(R)(\mathrm{mm} / 6 \mathrm{~h})$ for each station and on the other hand, the number of no-null precipitation data (every $6 \mathrm{~h}$ ) for each station (n). Total standard deviation $\sigma_{T}(R)$ will thus be used as an indicator of the proper class interval:

$\sigma_{T}=\sqrt{\sum_{i=1}^{m} \sigma_{i}^{2}(\bar{R})}$

where, $\sigma_{i}(\bar{R})$ is the standard deviation of the mean for station $\mathrm{i}$, given by:

$\sigma(\bar{R})=\frac{\sigma(R)}{\sqrt{n}}$

where,

$\sigma(\mathrm{R})=\sqrt{\frac{1}{n-1} \sum_{i=1}^{n}\left(R_{i}-\bar{R}\right)^{2}}$

In addition, a correction factor (CF) must be introduced in order to take into account the studied period of time and the number of stations reporting rain data. $\mathrm{CF}$ is defined by:

$\mathrm{CF}=\sqrt{t / m}$

where, $t$ is the number of months and $\mathrm{m}$ corresponds to the number of stations. Therefore:

$\sigma_{T}^{*}=\sigma_{T} . \mathrm{CF}$

Finally, the criterion based on parameter $\sigma_{T}^{*}(R)$ is shown in Table 1 . The proper class interval width yields a smooth exponential distribution for small rates of $R$ (represented by the stratiform component), while large anomalies (which are related to the contribution of convective systems) are present at higher intensities of precipitation.

1 The 6-h periods are pre-selected corresponding to synoptic times (at 00:00, 06:00, 12:00 and 18:00 UTC). 
Table 1. Criterion for the class interval width (CIW) selection.

\begin{tabular}{ll}
\hline$\sigma_{T}^{*}(\mathrm{~mm} / 6 \mathrm{~h})$ & CIW $(\mathrm{mm} / 6 \mathrm{~h})$ \\
\hline$(0,0.75]$ & 0.5 \\
$(0.75,1.5]$ & 1.0 \\
$(1.5,2.25]$ & 1.5 \\
$(2.25,3]$ & 2.0 \\
$(3,3.75]$ & 2.5 \\
$(3.75,4.5]$ & 3.0 \\
$(4.5,5.25]$ & 3.5 \\
$(5.25,6]$ & 4.0 \\
$>6$ & 5.0 \\
\hline
\end{tabular}

Once a suitable class interval is selected, a technique for partitioning surface precipitation is developed by creating two algorithms. The first algorithm is performed in order to determine the stratiform component. It identifies the points of minimum in the exponential distribution and fits an exponential curve to them. The first point of the distribution, corresponding to the lowest value of precipitation intensity $R$, is negligible and will not be taken into account in order to obtain the most accurate fit. The convective component $\mathrm{CP}$ (grey bars, in Fig. 2) is assessed by subtracting the exponential component (thin curve, representative of stratiform regime SP) from the total precipitation distribution TP (thick line).

The second algorithm is established to evaluate the critical intensity (Rc) which separates the precipitation into two different modes: those rainy events reporting an intensity higher than Rc are associated with a predominant convective regime, while episodes with an intensity lower than Rc are related to prevalent stratiform regime. The parameter $\mathrm{Rc}$ is assessed by means of the following iterative process (Fig. 3). A precipitation intensity Ro is selected as an initial condition; the algorithm will then search for an intensity value higher than Ro for which the convective component represents, at least, the $60 \%$ of the total accumulated precipitation corresponding to this specific intensity; if it does not find an intensity that verifies the imposed condition, the program will re-evaluate the stratiform component by a new exponential fitting, and the critical value will thus be searched again. This operation will be repeated as many times as needed in order to obtain Rc. However, if the iterative process tends to be infinite, it is obvious that the initial condition is wrong and a smaller Ro must be chosen. It is worth pointing out that the selection of Ro does not have any influence on the final critical intensity but in determining the amount of iterations to reach Rc.

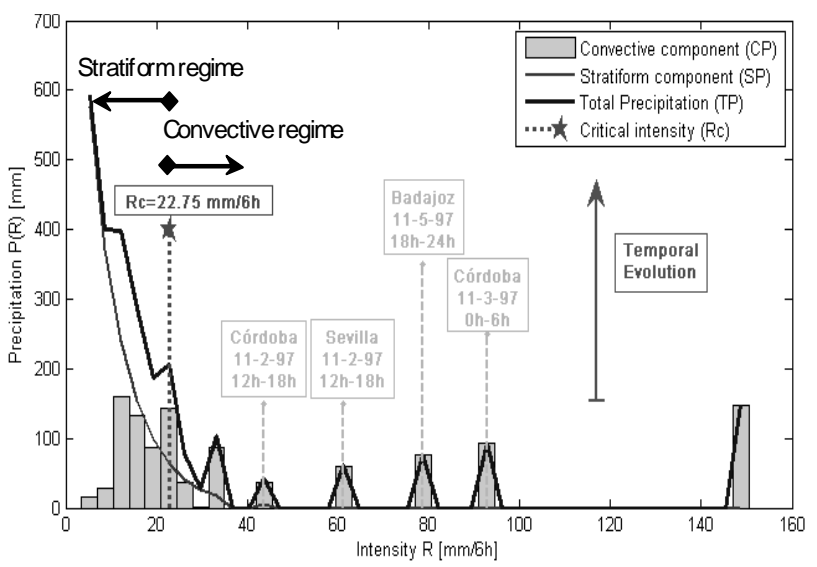

Fig. 2. Precipitation partition into convective and stratiform components. SW region of Spain, hydrological year 1998. The last grey bar $(R=148.75 \mathrm{~mm} / 6 \mathrm{~h})$ corresponds to an extremely intense precipitation event that took place in Huelva on 27 September 1997 with no dramatic consequences. The first grey bar on the "convective area" $(R=33.25 \mathrm{~mm} / 6 \mathrm{~h})$ corresponds to three rainy episodes that happened on Huelva, Sevilla and Badajoz at different stages of the hydrological year.

\section{Results and discussion}

\subsection{Brief synoptic study}

The synoptic situation leading to this severe weather episode is presented in Figs. 4 and 5. The geopotential field at the $500 \mathrm{hPa}$ level (Fig. 4a) shows an Atlantic extratropical trough approaching IP from the southwest, with the rising branch advecting warm and wet air masses through the Gulf of Cádiz. The low became deeper quickly and extended to lower levels just before the heavy rain event took place, as it can be seen in Fig. '4b: the center of low pressure is located in the middle of IP and affects the whole peninsula.

Subtropical areas are warmer provide large amounts of moisture which are transported by strong winds towards southwestern IP (Fig. 5). It must be highlighted that 1997 was a year characterized by negative annual NAO (North Atlantic Oscillation) index (Wallace and Gutzler, 1981) and an October-to-December negative monthly NAO index. Since the inverse link between NAO index and the precipitation pattern over southwestern IP has been proved (RodriguezPuebla et al., 1998 and 2001), we can assume that the storm track deviation to lower latitudes (related to NAO negative phase) plays an important role in the development and movement of the trough that affected IP during the studied event.

\subsection{Lagrangian particle simulation}

The Lagrangian model FLEXPART6.2 has been applied in order to characterize the atmospheric particles involved in the focused case. The event is described in terms of moisture 


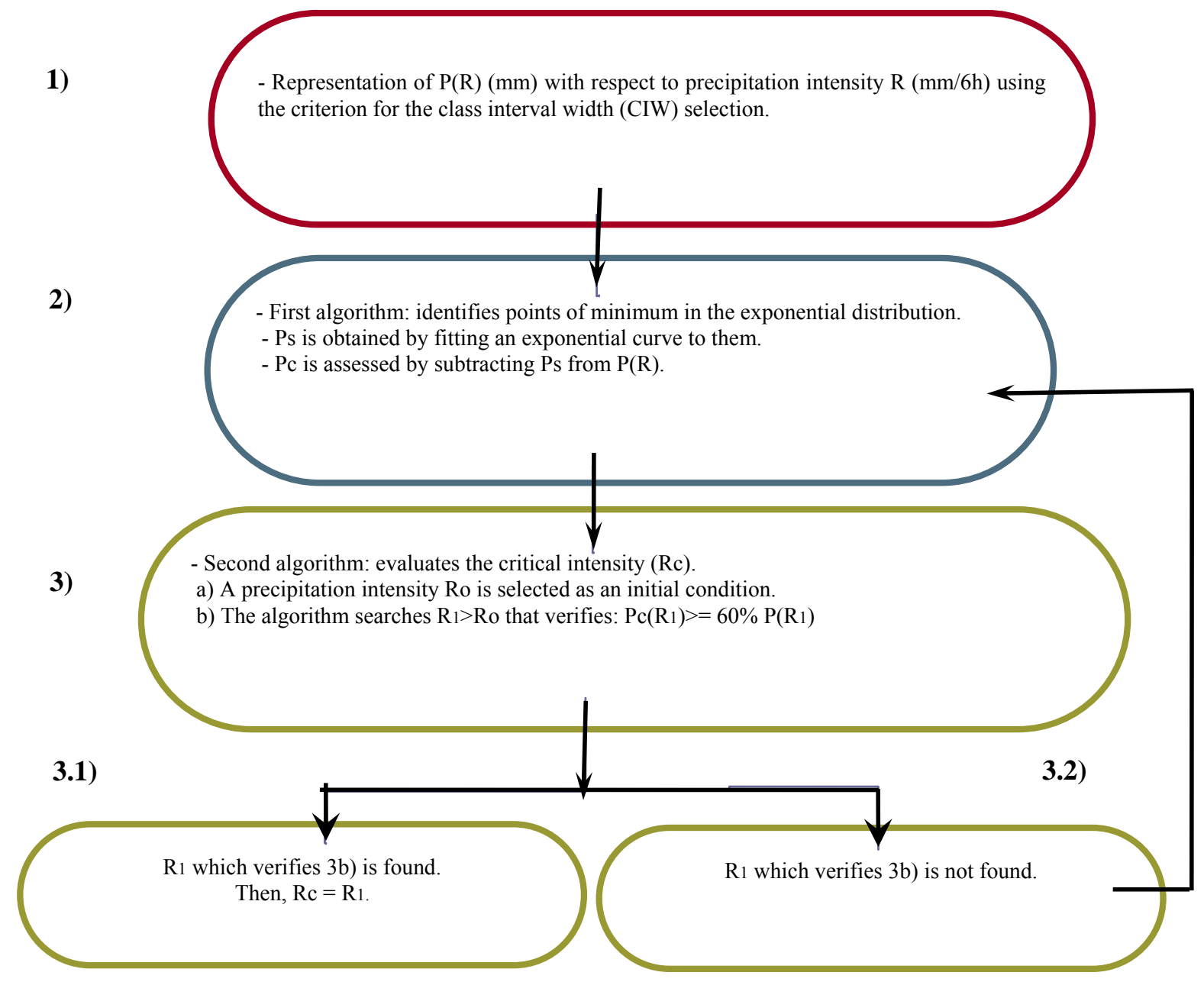

Fig. 3. Flow diagram representing the process for the selection of the critical intensity Rc. When Rc is not found, the process returns to the step 2) and a new exponential fitting is done. If this loop is repeated continually, then the initial condition Ro is wrong and a new initial condition Ro' (where, Ro' $<$ Ro) must be chosen.

content evolution by means of individual particle simulation along 3-day backward trajectories (Fig. 6). In particular, a half a million atmospheric particles have been analyzed in order to achieve this case study. Dry particles (dark) showed high-level paths according to the geostrophic wind. They displayed higher speed and were not responsible for the intense rain. However, wet atmospheric particles (in grey) traveled at lower levels, becoming moister and moister (darker) in their way towards IP. They reached Gulf of Cádiz, where they were probably lifted by convection (Figs. 7 and 8) to higher and colder levels, two days before the severe episode took place in Badajoz.

Therefore, the moist air masses involved in sixth of November 1997 MCS carried the available humidity from low latitudes: the moisture sources are located over a tropical area between $15^{\circ} \mathrm{N}-30^{\circ} \mathrm{N}$ and $15^{\circ} \mathrm{W}-25^{\circ} \mathrm{W}$ (Figs. 5 and $6)$.

\subsection{Thermodynamic instability}

Thermodynamic indices such as SWEAT, KI and CAPE have been also calculated in order to complete the analysis and to give a thorough weather frame taking into account the atmospheric instability. Table 2 depicts these indices derived from radiosounding dataset of Gibraltar station.

Both the Severe Weather Threat index (SWEAT) and K Index (KI) show clearly the degree of thermal atmospheric instability associated with the development of convective systems. They exceeded the $90 \%$ percentile (values higher than 200 and 25, respectively) during the previous days to the Badajoz episode. However, other thermodynamic indices like SI (Showalter Index), LI (Lifted Index) or TT (Total Totals) do not exhibit significant values. Indeed, CAPE (Convective Available Potential Energy) index, normally used as a method to evaluate the convective potential of the atmosphere, shows negligible values: the maximum CAPE 
(a)

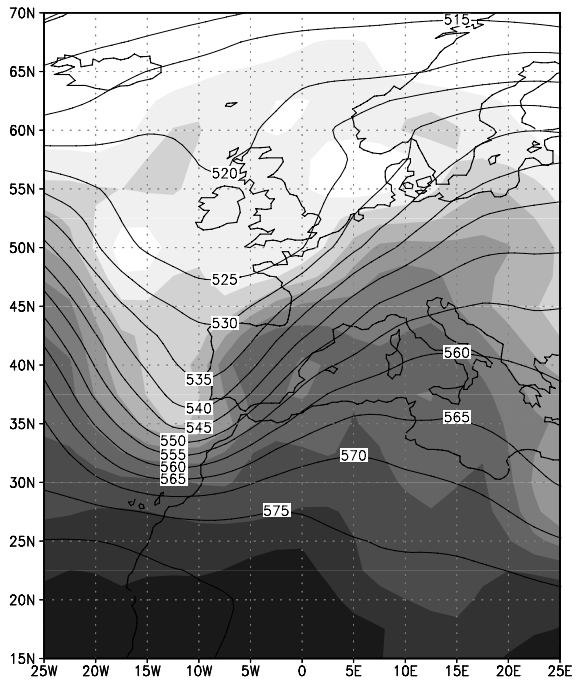

(b)

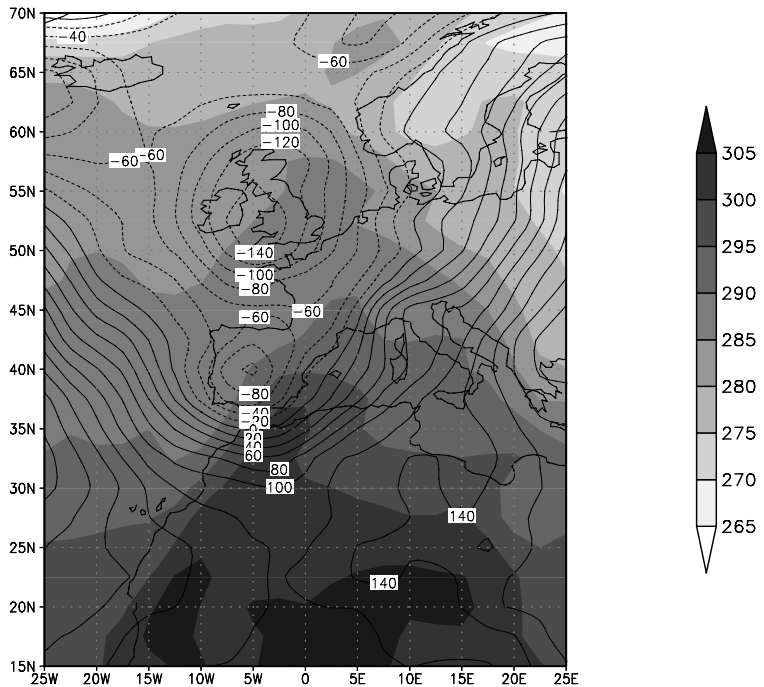

Fig. 4. Temperature (shaded, in $K$ ) and geopotential (black lines, in gpm) at (a) $500 \mathrm{hPa}$ level (geopotential dam), (b) $1000 \mathrm{hPa}$ level. 00:00 UTC, 6 November 1997.

Table 2. Thermodynamic indices obtained every $12 \mathrm{~h}$. There are missing data for 00:00 and 12:00 UTC 3 November 1997, 12:00 UTC 4 November 1997 and 00:00 UTC 6 November 1997 CAPE is in J/kg; SWEAT, KI, SI, LI and TT are dimensionless. Instability thresholds are: $\mathrm{CAPE}>1000 \mathrm{~J} / \mathrm{kg}, \mathrm{SWEAT}>200, \mathrm{KI}>25, \mathrm{SI}<4, \mathrm{LI}<0$ and $\mathrm{TT}>44$.

\begin{tabular}{lllllll}
\hline Indices for Gibraltar & $\begin{array}{l}2 \text { November } 1997 \\
\text { 00:00 UTC }\end{array}$ & $\begin{array}{l}\text { 2 November 1997 } \\
12: 00 \text { UTC }\end{array}$ & $\begin{array}{l}\text { 4 November 1997 } \\
\text { 00:00 UTC }\end{array}$ & $\begin{array}{l}\text { 5 November 1997 } \\
\text { 00:00 UTC }\end{array}$ & $\begin{array}{l}\text { 5 November 1997 } \\
\text { 12:00 UTC }\end{array}$ & $\begin{array}{l}\text { 6 November 1997 } \\
12: 00 \text { UTC }\end{array}$ \\
\hline SWEAT & 273.4 & 320.1 & 333.9 & 180.4 & 300.8 & 116.9 \\
KI & 30.3 & 32.9 & 24.9 & 30.6 & 30.1 & 26.1 \\
SI & 3.3 & 1.7 & 4.4 & 3.8 & 4.3 & 4.4 \\
LI & 2.2 & 1.7 & 2.0 & 0.3 & 3.8 & 0.4 \\
TT & 45.4 & 46.2 & 41.4 & 43.7 & 41.0 & 47.4 \\
CAPE & 0 & 4.6 & 149.2 & 47.5 & 19.1 & 172.2 \\
\hline
\end{tabular}

during the examined period corresponds to $172.2 \mathrm{~J} / \mathrm{kg}$, which is clearly below the threshold.

Since Gibraltar station is located rather far from Badajoz, the place where this severe weather episode took place, these indices need to be interpreted with caution.

\subsection{Dynamic instability}

Maps of dynamic parameters like $\boldsymbol{Q}$ vector divergence and potential vorticity anomaly at $330 \mathrm{~K}$ isentropic surface provide useful and visual information about regions of subsidence or lifting air. In order to characterize the dynamic instability, the divergence of $\boldsymbol{Q}$ vector (dQ) at 500 (Fig. 7) and $850 \mathrm{hPa}$ (not shown) has been calculated (Jusem and Atlas, 1997). The mathematical expression of $d Q$ is:

$$
\left(\nabla^{2}+\frac{f^{2}}{\sigma} \frac{\partial^{2}}{\partial p^{2}}\right) \omega=\frac{-2}{\sigma} \nabla \cdot \boldsymbol{Q}
$$

where $\omega$ is the isobaric vertical speed, $\omega=d p / d t . \sigma$ is the stability parameter, that is defined as follows: $\sigma=\frac{-\alpha}{\theta} \frac{\partial \theta}{\partial p}$, where $\alpha$ is the specific volume and $\theta$ the potential temperature.

The first term of Eq. (7) is proportional to $-\mathrm{r} \omega$. Therefore, if there is negative divergence it implies the air is moving upwards because of the instability $(\omega<0)$. However, if divergence is present at certain level then stability can be inferred.

Figure 7 shows large dQ anomalies at $500 \mathrm{hPa}$ over southwestern IP. Positive anomalies (bright) indicate air mass subsidence, while negative anomalies (dark) represent lifting air, where MCSs could have been originated by strong convection.

Potential vorticity anomalies (PV) were calculated by subtracting the dynamical tropopause value, defined as $2 \mathrm{PV}$ units ( $1 \mathrm{PV}$ unit $=10^{-6} \mathrm{~km}^{2} \mathrm{~kg}^{-1} \mathrm{~s}^{-1}$ ). Positive values were obtained at IP (Fig. 8), with one local maximum of PV fitting with the trough over Gulf of Cadiz and pointing out the region where convection was likely to develop. These 

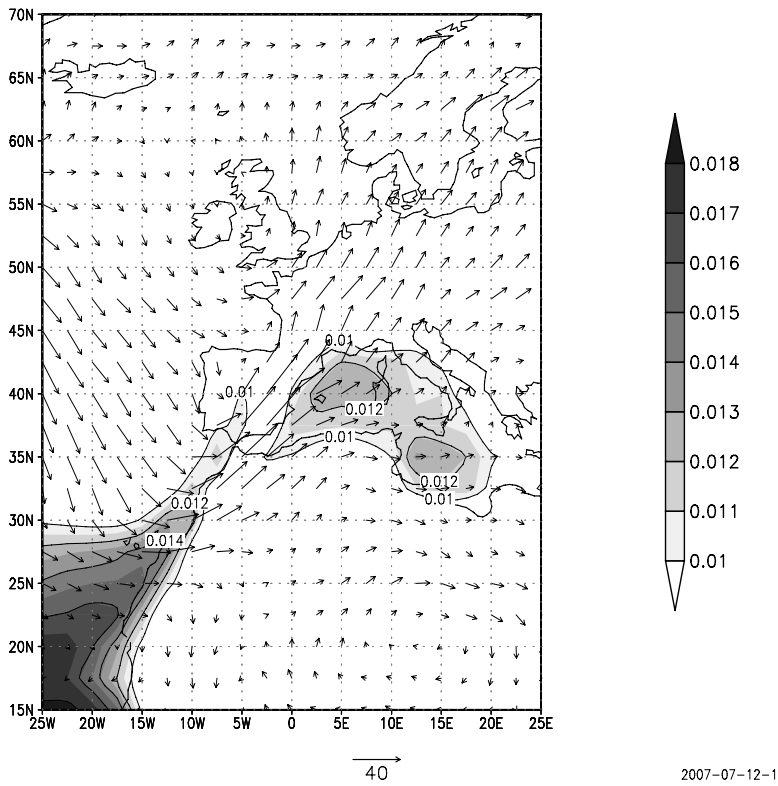

Fig. 5. Specific humidity distribution $(\mathrm{kg} / \mathrm{kg})$ at $1000 \mathrm{hPa}$ and wind $(\mathrm{m} / \mathrm{s})$ at $700 \mathrm{hPa}$ level. 00:00 UTC 6 November 1997.

remaining dynamic instability structures were detected during the whole heavy rain episode.

\subsection{Precipitation partition}

The exponential distribution mentioned in Sect. 2 is always present independent of the averaging time interval (Tremblay, 2005). In this work, the complete hydrological year 1998 has been considered in order to classify the precipitation and identify the main convective systems involved in the heavy rain events registered during 2-5 November in the southwestern IP.

As it is shown in Fig. 2, the class interval width corresponds to $3.5 \mathrm{~mm} / 6 \mathrm{~h}$ and the critical intensity (Rc, vertical dotted line) is equal to $22.75 \mathrm{~mm} / 6 \mathrm{~h}$. Rainfall episodes reporting higher intensity are associated with predominant convective regime while rainfall events with an intensity lower than $\mathrm{Rc}$ are related to prevalent stratiform regime. The severe precipitation episode in Badajoz $(76 \mathrm{~mm} / 6 \mathrm{~h}$ ) is clearly situated on the convective area, as it was expected. During the previous three days, three heavy rain events were detected in nearby regions south of Badajoz: in Sevilla $(61.25 \mathrm{~mm} / 6 \mathrm{~h})$ and Córdoba (twice: 43.75 and $92.75 \mathrm{~mm} / 6 \mathrm{~h}$ ). They were caused by convective systems related to the trough as this was crossing through the Atlantic Ocean and the southwestern region of IP. The total precipitation amounts observed in the five selected stations during the period examined are depicted in Table 3. As it can be seen, the three stations affected by MCSs are those where the largest rainfall amounts were recorded.
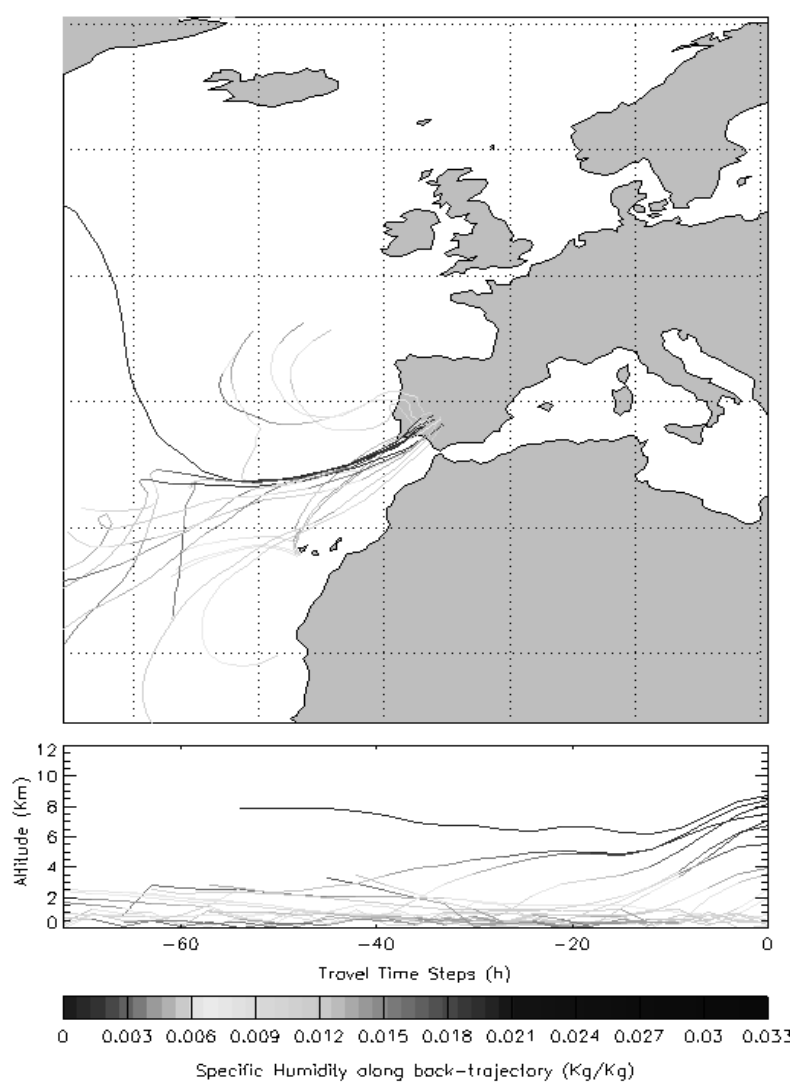

Fig. 6. Trajectories and moisture evolution for particles involved in MCS of Badajoz. 00:00 UTC 6 November 1997. The Lagrangian simulation is in good agreement with the specific humidity distribution shown in Fig. 5, as well as with the wind pattern.

Table 3. Daily precipitation $(\mathrm{mm} / 24 \mathrm{~h})$ observed during the examined period. "Total" is the precipitation $(\mathrm{mm})$ registered from 2 November to 5 November 1997.

\begin{tabular}{llllll}
\hline Stations: & Cádiz & Huelva & Sevilla & Córdoba & Badajoz \\
\hline 2 November 1997 & 29.2 & 22.5 & 96.6 & 63.1 & 49.3 \\
3 November 1997 & 17.5 & 10.5 & 29.2 & 108.6 & 9.7 \\
4 November 1997 & 13.2 & 2.1 & 1.1 & 3.3 & 0.5 \\
5 November 1997 & 10.6 & 15.3 & 15.1 & 9.0 & 117.3 \\
Total & 70.5 & 50.4 & 142 & 184 & 176.8 \\
\hline
\end{tabular}

\section{Conclusions}

The main purpose of this work is to assess the prevailing synoptic conditions, as well as detailing the mesoscale effects by means of moisture sources and dynamic and thermodynamic instability analysis for the severe weather episode studied here.

The proposed procedure for partitioning precipitation into stratiform and convective components proves that the 


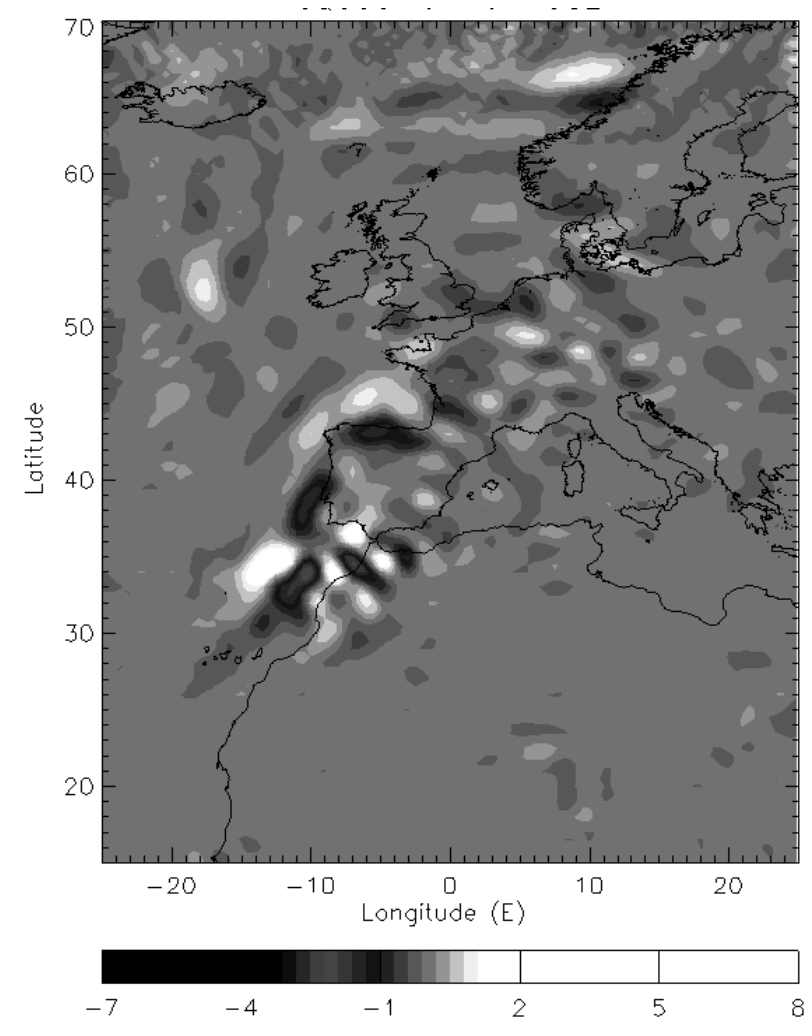

Fig. 7. $\boldsymbol{Q}$ vector divergence $\left[k P a \quad \mathrm{~m}^{-2} \mathrm{~s}^{-1}\right]$ at $500 \mathrm{hPa}$ level. 00:00 UTC 6 November 1997. Spatial resolution: $0.5^{\circ} \times 0.5^{\circ}$.

Badajoz heavy rain event on 6 November 1997 was associated with predominant convective regime. This technique, based on statistical properties of in situ rain dataset, allows to identify convective systems without using satellite images and establish the main features of the two different modes of precipitation.

A thermodynamic analysis shows that this rainy event was not associated with thermally unstable conditions. Since these indices do not exhibit significant values, we can state that the dynamic instability played a fundamental role in the development of a MCS in Badajoz. The strong convection related to the detected dynamic instability structures, along with large amounts of moisture advected by a trough affecting IP, were ultimately responsible for the observed precipitation rates.

Finally, backward trajectories by using the Lagrangian model FLEXPART6.2 provide a detailed and new perspective for the analysis of MCSs. The assessment of the origin and the trajectories of different air masses allows a better understanding of hazardous rainfall episodes and provides a helpful tool for forecasting and warning against floods and potential damages.

Acknowledgements. The authors wish to thank the National Meteorological Institute of Spain for providing the precipitation data

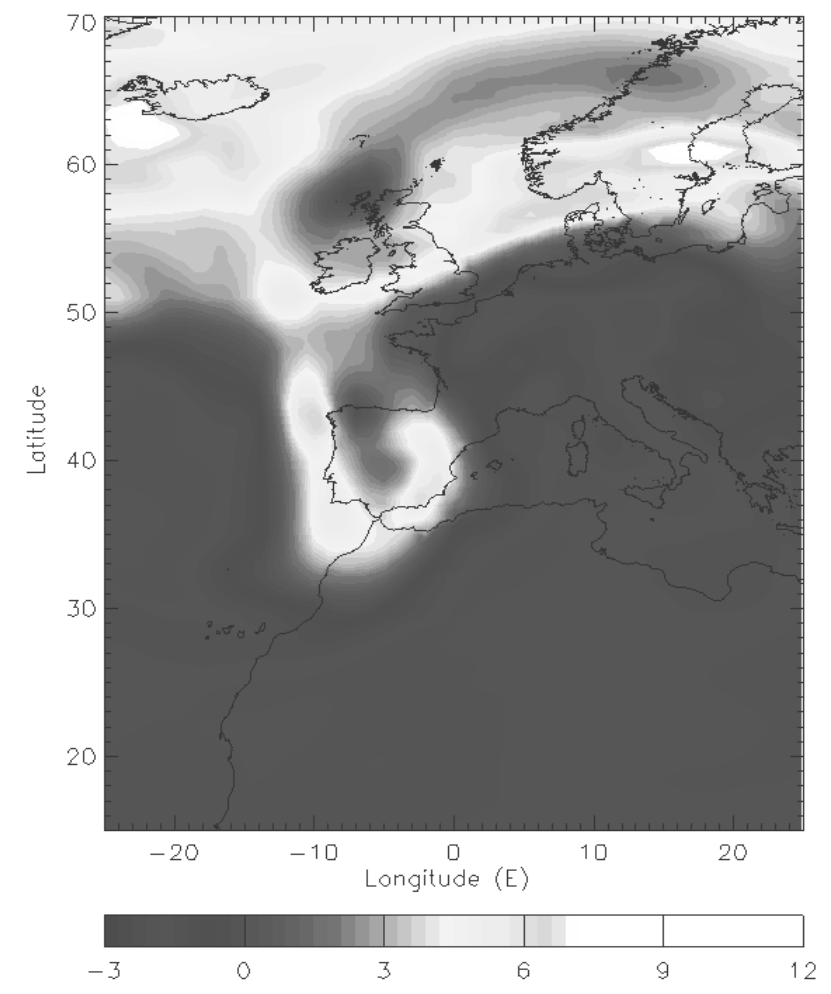

Fig. 8. Potential vorticity anomalies (in Potential Vorticity Unit, $1 \mathrm{PVU}=10^{-6} \mathrm{Km}^{2} \mathrm{~s}^{-1} \mathrm{Kg}^{-1}$ ) at the $330 \mathrm{~K}$ isentropic surface. 00:00 UTC 6 November 1997. Spatial resolution: $0.5^{\circ} \times 0.5^{\circ}$.

and ECMWF for the reanalysis data. The Ministerio de Educación y Ciencia supported this study through the DINPRE (DINámica de la PREcipitación) project (CGL2004-05187-C03-01/CLI).

Edited by: S. C. Michaelides

Reviewed by: two anonymous referees

\section{References}

Houze, R. A.: Cloud Dynamics, Internatonal Geophysics Series, Vol. 53, Academic Press, 573 pp., 1993.

Houze, R. A.: Stratiform precipitation in regions of convection: A meteorological paradox?, B. Am. Meteorol. Soc., 78, 21792196, 1997.

Jusem, J. C. and Atlas, R.: Diagnostic evaluation of vertical motion forcing mechanisms by using Q-vector partitioning, Mon. Weather Rev., 126, 2166-2184, 1997.

Lang, S., Tao, W. K., Simpson, J., and Ferrier, B.: Modeling of convective - stratiform precipitation processes: Sensivity to partitioning methods, J. Appl. Meteor., 42, 505-527, 2003.

Rodríguez-Puebla, C., Encinas, A. H., Nieto, S., and Garmendia, J.: Spatial and temporal patterns of annual precipitation variability over the Iberian peninsula. Int. J. Climatol., 18, 299-316, 1998.

Rodríguez-Puebla, C., Encinas, A. H. and Sáenz, J.: Winter precipitation over the Iberian peninsula and its relationship to circulation indices, Hydrol. Earth Sy. Sci., 5, 233-244, 2001. 
Rogers, R. R. and Yau, M. K.: A short course in cloud physics, Pergamon Press, 196-205, 1989.

Stohl, A., Hittenberger, M., and Wotawa, G.: Validation of the Lagrangian particle dispersion model FLEXPART against large scale tracer experiment data, Atmos. Environ., 32, 4245-4264, 1998.

Stohl, A., and Thompson, D. J.: A density correction for Lagrangian particle dispersion models, Bound.-Layer Meteor., 90, 155-167, 1999.
Tremblay, A.: The stratiform and convective components of surface precipitation, J. Atmos. Sci., 62, 1513-1528, 2005.

Trenberth, K. E., Dai, A., Rasmussen, R.M., and Pearson, D.: The changing character of precipitation, B. Am. Meteorol. Soc., 84, 1205-1217, 2003.

Wallace, J. M. and Gutzler, D. S.: Teleconnection in the geopotential height field during the Northern Hemisphere winter, Mon. Weather Rev., 109, 784-812, 1981. 